\title{
e-Government Ethics : a Synergy of Computer Ethics, Information Ethics, and Cyber Ethics
}

\author{
Arief Ramadhan, Dana Indra Sensuse, Aniati Murni Arymurthy \\ Faculty of Computer Science \\ University of Indonesia \\ Depok, Indonesia
}

\begin{abstract}
Ethics has become an important part in the interaction among humans being. This paper specifically discusses applied ethics as one type of ethics. There are three applied ethics that will be reviewed in this paper, i.e. computer ethics, information ethics, and cyber ethics. There are two aspects of the three applied ethics that were reviewed, i.e. their definition and the issues associated with them. The reviewing results of the three applied ethics are then used for defining e-Government ethics and formulating the issues of e-Government ethics. The eGovernment ethics position, based on the previous three applied ethics, is also described in this paper. Computer ethics, information ethics and cyber ethics are considered as the foundations of e-Government ethics and several others applied ethics could enrich the e-Government ethics.
\end{abstract}

Keywords- e-Government; Ethics; Applied Ethics; Computer Ethics; Information Ethics; Cyber Ethics

\section{INTRODUCTION}

Basically, the ethics regulates human behavior in doing something, whether someone doing the right thing or wrong thing. In determining whether someone doing is true or not, ethic is more concerned to the acceptability by his social environment. In this sense, ethics are social centric. An individual can not properly claim that his action is right ethically, unless their social environment consider it correct. This is consistent with what is stated in the [3], that ethic is relationship conduct pattern based on respect own rights and others against their environment.

Ethics is closely related to philosophy, so that several definitions of ethics would involve the word philosophy in it. As stated in [4], ethics is a branch of philosophy that is concerned with human conduct, more specifically the behavior of individuals in society. Other definition in [5] says that ethics is a branch of philosophy that deals with what is considered to be right and wrong. In [6], it is described that Ethics is a branch of philosophy that studies morals and values. In addition, another definition states that the field of ethics (or moral philosophy) involves systematizing, defending, and recommending concepts of right and wrong behavior [7].

There are two aspects in the definition of ethics: being able to determine what is right or wrong, good or bad and a commitment to doing what is right and good [4]. Ethics examines the rational justification for our moral judgments; it studies what is morally right or wrong, just or unjust [4]. Ethics are a subset of values: a value applies to things that are desired as well as what one ought to do, and can include such concepts as wealth, happiness, success, and fulfillment [4].

If we examine some various explanations above, it appears that ethics is closely related to morality. However, ethics can be not the same as morality. As hinted in [8], morality will be understood as the set of norms that guide our factual behavior whereas ethics is seen to be the theory and reflection of morality.

As stated in [7], philosophers today usually divide ethical theories into three general subject areas: metaethics, normative ethics, and applied ethics. Metaethics investigates where our ethical principles come from, and what they mean [7]. Metaethical answers to these questions focus on the issues of universal truths, the will of God, the role of reason in ethical judgments, and the meaning of ethical terms themselves [7]. When compared to normative ethics and applied ethics, the field of metaethics is the least precisely defined area of moral philosophy [7]. We may define metaethics as the study of the origin and meaning of ethical concepts [7].

Unlike the metaethics, normative ethics takes on a more practical task, which is to arrive at moral standards that regulate right and wrong conduct [7]. This may involve articulating the good habits that we should acquire, the duties that we should follow, or the consequences of our behavior on others [7]. In a sense, it is a search for an ideal litmus test of proper behavior [7]. The Golden Rule is a classic example of a normative principle: We should do to others what we would want others to do to us [7].

The key assumption in normative ethics is that there is only one ultimate criterion of moral conduct, whether it is a single rule or a set of principles [7]. Three strategies that are associated with normative ethics are also revealed in the [7], i.e. virtue theories, duty theories, and consequentialist theories.

Applied ethics can be classified into several types. This division is generally adapted to the needs of the social environment. Fieser in the [7], states that Applied ethics is the branch of ethics which consists of the analysis of specific, controversial moral issues. Other statements is revealed by Kaddu in [4], that ethics leads to a set of rules of conduct for specific situations; basic ethical principles guide the 
development of standards for specific professions and groups. What was put forward by Kaddu is highly relevant to applied ethics.

This paper will attempt to define what the meaning of eGovernment ethics. The definition will be associated with the applied ethics. There are three applied ethics, in the world of computers science, which will be used as a reference, i.e. computer ethics, information ethics, and cyber ethics. Therefore, this paper will also try to discuss these three applied ethics from several perspectives. Some issues related to the three applied ethics will also be identified.

In addition this paper will also describe the position of the e-Government ethics against computer ethics, information ethics and cyber ethics. A diagram of this concept will be used to describe the position of the e-Government ethics.

\section{A REVIEW ON COMPUTER ETHICS DEFINITION AND ISSUES}

At this time, there are several emerging applied ethics, such as environment ethics, media ethics, etc. Several applied ethics that related to computer science world is computer ethics, information ethics and cyber ethics.

As the name implies, computer ethics is closely related to the use of computers by humans. We suggest that there are two things in the computer ethics that can be observed, i.e. whether the computer is used to do the right thing or the computers are used correctly.

In [9], it is revealed that computer ethics is not simply ethics rotely applied to computing. Computer ethics has two parts: (i) the analysis of the nature and social impact of computer technology and (ii) the corresponding formulation and justification of policies for the ethical use of such technology [9].

Computer ethics is a standard for computer use, signifying the prevention of copyright infringement, such as the reproduction of software, invasion of privacy, and circulation of objectionable material [10]. Computer ethics is made to research about security and it's beneficial aspects [11]. Computer ethics is also used to refer to professional ethics for computer professionals such as ethical codes of conduct that can be used as guidelines for an ethical case [12]. Lee and Chan, in [13], suggest that the work of computer ethics is not to create a new system of ethics but rather to apply traditional ethics and to extend them to cover situations that are attributed to computers.

Other interesting opinions related to the computer ethics can be seen in the [14]. The paper has presented computer ethics as neither a list of ethical principles to obey, nor a technology deprived of certain values while implementing those principles. Thus, computer ethics urges scholars to revisit computer technology and its values [14]. Even though computer ethics is a field related to and in between science and ethics, it is a unique and holistic discipline providing principles for understanding, conceptualization and computer technology use [14].
Brey in [15] suggests that there exist two parts of computer ethics, i.e. mainstream computer ethics and disclosive computer ethics. We consider, in accordance with our focus, mainstream computer ethics is relevant to our discussion.

In mainstream computer ethics, a typical study begins by identifying a morally controversial practice, like software theft, hacking, electronic monitoring, or internet pornography [15]. Next, the practice is described and analyzed in descriptive terms, and finally, moral principles and judgments are applied to it and moral deliberation takes place, resulting in a moral evaluation, and optionally, a set of policy recommendations [15]. There are three features of mainstream computer ethics proposed in [15], i.e. (1) Mainstream computer ethics focuses on existing moral controversies; (2) Its focus is on practices, i.e. the individual or collective behavior of persons, and it aims to evaluate and devise policies for these practices; (3) Its focus usually is on the use of computer technology, as opposed to, e.g., its design or advertisement.

Moor suggests that what is special about computer ethics is that it has a continually large number of evolving situations which are difficult to conceptualize clearly and for which it is hard to find justified ethical policies [9]. In summary, what is unique about computer ethics is computing technology itself, and what makes computer ethics different as a field of ethics is their scope, depth, and novelty of ethical situations for which conceptual revisions and policy adjustments are required [9].

From some of the above explanations, it can be concluded that there are several issues related to computer ethics, i.e. reproduction of software, invasion of privacy, circulation of objectionable material, and security. Several other issues are software theft, hacking, electronic monitoring, and internet pornography. Some of these issues can also appear in information ethics or cyber ethics.

\section{A REVIEW ON INFORMATION ETHICS DEFINITION AND ISSUES}

In simple terms, information ethics can be interpreted as ethics in the using, accessing and disseminating the information. In this case, the information is used for the right things, the information accessed in the right way, and the information is delivered correctly to the hand who have the rights.

Information ethics has been developed since the 1980s, encompassing areas such as computer ethics and global information ethics [10]. Capurro and Britz, in [16], stated that information ethics is not only about norms, but also about our critical reflection on the visions and options for better lives in the digital age.

Information ethics is an open space of reflection where commonalities and differences, theoretical as well as practical, can be discussed without the immediate pressure of decision making [16]. Information ethics is the new ecological ethics for the information environment [17]. Information ethics is essentially concerned with the question of who should have access to what information [18]. Information ethics relates to questions of ethics in terms of information or an informationoriented society [10]. This includes the standard for judging 
behavior of an individual or a member of community and classifying these as moral or immoral [10].

From some of the above explanations, it can be seen that information ethics is closely related to environmental and social. As revealed in [19], that information ethics is one aspect of a much larger philosophy known as social ethics.

It is revealed in [17], that we have to fight any kind of destruction, corruption, pollution, depletion (marked reduction in quantity, content, quality, or value) or unjustified closure of the infosphere, what shall be referred to here as information entropy. The ethical use of ICT and the sustainable development of an equitable information society need a safe and public infosphere for all, where communication and collaboration can flourish, coherently with the application of civil rights, legal requirements and the fundamental freedoms in the media [17].

Information ethics in the future should be a discipline that carries out four functions, i.e. : (1) information ethics is prescriptive ethics; (2) information ethics is preventive ethics; (3) information ethics is transformative ethics; and (4) information ethics must be universally global ethics, not one or the other, but must consist of both global and local disciplines [10]. Furthermore, in [10] also stated that for the proper use of information in an information society, the education relating to information ethics may present four goals, i.e. (1) respect for others must be cultivated; (2) although sharing beneficial information is welcome, other people's intellectual property right must not be infringed; (3) various forms of information will be used productively; and (4) telecommunications and the Internet will be used for acceptable time periods so that it does not harm actual life.

There are several issues related to information ethics. Several issues are emerged with different names or from different sources, but its essence remains the same. One of the most important topics in information technology ethics is privacy [20]. Fallis, in [18], saying that the core issues of information ethics include intellectual freedom, equitable access to information, information privacy, and intellectual property. In addition, in [19], it is also stated the two major issues of information technology, i.e. the conflict between observing others' privacy, and the simultaneous pursuit of individual freedom and autonomy. Another issue related to information ethics is responsibility and accountability. This is in line with what is also revealed in [19], that information ethics deals with the moral conduct of information-users based on their responsibility and their accountability.

\section{A ReVIEW ON Cyber ETHICS Definition AND ISSUES}

"Cyber" is a prefix used to describe people, things, or ideas that are connected with computers and the internet [21]. Therefore, cyber ethics is closely related to the development of internet technology, so that some definition of cyber ethics will include the internet or online terms in it. Indeed, some sources call cyber ethics with internet ethics. In this paper, the term cyber-ethics and internet ethics can interchangeable with each other

Cyber ethics is really about social responsibility in cyberspace [22]. As stated in [10], Cyber ethics is a system of standards that prescribe morality and immorality in cyberspace, signifying the preservation of freedom of expression, intellectual property, and privacy. Other definition of cyber ethics can be found in [23], that is cyber ethics is the discipline dealing with what is good and bad, and with moral duty and obligation as they pertain to online environments and digital media.

Lin, in [24], call cyber ethics as an internet ethics. In the paper, Lin stated that the right or wrong about the utility of internet by mankind can be called internet ethics. The utility of internet by mankind includes interpersonal communication, information's delivery, research, storage and so on [24].

It could be argued, that all of ethics, which applies in the computer ethics and information ethics can also apply on cyber ethics, but only focused on its application to the internet. As stated in the [25], the term of internet ethics can be thought as a special extention of computer ethics, but the main difference between them is that internet ethics is dealing with the behaviors performed in internet.

The challenge for cyber ethics is to discuss principles of morality that can guide human action so that people are empowered to establish a sustainable, participatory global information society [26]. Cyber ethics can discuss real possibilities of development of the information society and criticize ideologies that portray the information society in uncritical and one-dimensional ways [26]. By e-mail or newsgroup, any sort of opinions and thoughts can be spread all over the world. On the one hand, it can help people communicate, express opinions and thoughts, and get responses from other people fast; on the other hand, it also may be misused, such as quite a few bothering ads, fraud letters, nonsense articles interfering seriously with other people's chances to get useful information [24].

Some of cyber ethics issues raised in [23], i.e. plagiarism, copyright, hacking, fair use, file sharing, online etiquette protocols, posting incorrect/inaccurate information, cyberbullying, stealing or pirating software, music, and videos, online gambling, gaming, and internet addiction. Several other current cyber ethics issues are raised in [27], i.e. privacy, security, electronic monitoring of employees, collection and use of personal information on consumers, and identity theft.

\section{The Definition, Position And Issues of E- GOVERNMENT ETHICS}

Simply, e-Government ethics can be defined as ethics in the use of e-Government system, either to insert or update content into the system or to get content from the system. However, to give more in-depth understanding, we will try to explain it further by reviewing the definition of e-Government and see how e-Government system is implemented.

e-Government is the use of Information Technology (IT) by public sector organizations [1]. Other definition of eGovernment is public sector use of the internet and other digital devices to deliver services, information, and democracy itself [2].

e-Government is also an information system [1]. So, it can be said that several theories about the information system can 
be applied in e-Government. However, e-Government is different from ordinary information system that is generally targeting the private sector. The main orientation of eGovernment is the accessibility of information by the public, rather than financial income [1].

Because the target of e-Government is the public sector, then the e-Government systems are generally built based on the web technology. This technology is used because it has ability to reach people quickly and widely. This also implies that the users of e-Government systems will generally using computer in accessing the system.

e-Government has one of the characteristics of postmodernism, that is the social construct [30]. This shows the presence of interaction between human beings in eGovernment. The interaction of course need a set of rules to regulate it. One set of rules that can be applied is ethics.

Based on the above definition and description regarding to e-Government, then it can be said, that in e-Government, it could apply three applied ethics, i.e. computer ethics, information ethics and cyber ethics. But, beside these three applied ethics, in e-Government, it also could apply some others applied ethics.

e-Government is not simply about information technology or website, but there are also some aspects of management in it. As revealed in [1], that e-Government are socio-technical and there are two aspects in e-Government, i.e. the technical aspects (technology) and managerial aspects. This means, that there is other ethics that can be applied, that is management ethics.

Moreover, one of the actors involved in e-Government is the business. So, the business ethics can also be applied in eGovernment.

There is another aspect in e-Government, that is the aspect of the object being observed. For example, in [28], it is proposed a new paradigm in e-Government called e-Livestock. From the definition of e-Livestock, it can be seen that the object related to e-Livestock is the animal, i.e. cows or buffaloes. In this case, in addition to several ethics already discussed above, there are other ethics that can be related to eGovernment, that is the ethics of animal treatment.

Computer ethics, information ethics, and cyber ethics can be said as the foundations of e-Government ethics, and there are another applied ethics as the complement of the eGovernment ethics. Fig. 1 shows the position of e-Government ethics in relation to the other applied ethics.

Based on Fig. 1, it can also be concluded that some issues related to computer ethics, information ethics, and cyber ethics, which has been mentioned previously, could also become an issue in e-Government ethics. But, of course, it could be added with other issues, such as the issue of sensitivity of the information as revealed in [29], or the issue of trustworthiness of the content of e-Government system.

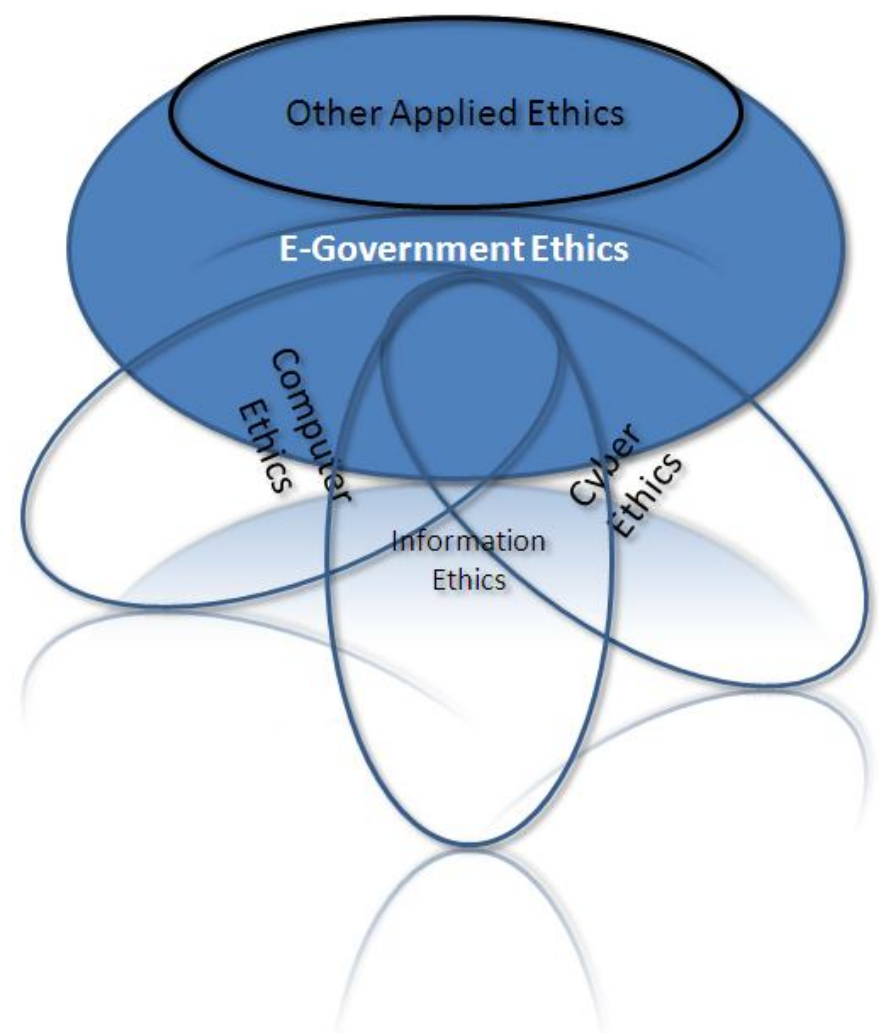

Figure 1. e-Government ethics position related to computer ethics, information ethics, cyber ethics and other applied ethics.

\section{CONCLUSIONS}

This paper has summarized the definitions and several issues related to computer ethics, information ethics and cyber ethics. The three applied ethics turns out to be a foundation for e-Government ethics.

The definition of the e-Government ethics has been given in this paper. The position of e-Government ethics among computer ethics, information ethics, cyber ethics, and other applied ethics (such as the ethics of management, business, object treatment, etc.) is also described in this paper.

This paper can be the starting point of research about eGovernment ethics. In the future, there could be many other applied ethics and issues that can be identified and added to the e-Government ethics presented in this paper.

\section{REFERENCES}

[1] R. Heeks, Implementing and Managing eGovernment An International Text, London, England : SAGE Publications, 2006.

[2] D. M. West, Digital Government Technology and Public Sector Performance, New Jersey, USA : Princeton University Press, 2005.

[3] A. Shalbaf, "A view of Problems and Practical Pattern of Promotion of Ethics in Educational Organizatons," Iranian Journal of Ethics in Science and Technology, vol. 4, no. 1, 2009.

[4] S. B. Kaddu, "Information Ethics: a student's perspective," International Review of Information Ethics, vol. 7, 2007. 
[5] U. Averweg and G. Erwin, "Towards a Code of Cyberethics for a Municipality in South Africa," in Proceedings of the Fifth International Conference on Electronic Business, 2005, pp. 522-527.

[6] R. Yucel, H. Elibol, and O. Dagdelen, "Globalization and International Marketing Ethics Problems," International Research Journal of Finance and Economics, issue. 26, pp. 93-104, 2009.

[7] J. Fieser, "Ethics", Internet Encyclopedia of Philosophy, A PeerReviewed Academic Resources. [Online]. Available: http://www.iep.utm.edu/ethics/, 2009.

[8] B. C. Stahl, "Information, Ethics, and Computers: The Problem of Autonomous Moral Agents," Minds and Machines, vol. 14, pp. 67-83, 2004.

[9] J. H. Moor, "Reason, Relativity, and Responsibility in Computer Ethics," Computers and Society, pp. 14-21, March 1998.

[10] H. Ki and S. Ahn, "A Study on the Methodology of Information Ethics Education in Youth," International Journal of Computer Science and Network Security, vol. 6, no. 6, pp. 91-100, 2006.

[11] M. Namayandeh and H. Taherdoost, "Review Paper on Computer Ethics and Related Research Models," Journal of Open Problems in Science and Engineering, vol. 1, no. 1, pp 42-47, 2009.

[12] R. Heersmink, J. V. D. Hoven, N. J. V. Eck, and J. V. D. Berg, "Bibliometric Mapping of Computer and Information Ethics," CWTS Working Paper Series, p. 13, 2010.

[13] W. W. Lee and A. K. K. Chan, "Computer Ethics: an Argument for Rethinking Business Ethics", in The 2nd World Business Ethics Forum: Rethinking the Value of Business Ethics, 2008.

[14] A. Kuzu, "Problems Related to Computer Ethics: Origins of The Problems and Suggested Solutions," The Turkish Online Journal of Educational Technology, vol. 8, issue. 2, pp. 91-110, 2009.

[15] P. Brey, "Disclosive Computer Ethics: The Exposure and Evaluation of Embedded Normativity in Computer Technology," Computers and Society, vol. 30, no. 4, pp. 10-16, 2000.

[16] R. Capurro and J. B. Britz, "In search of a code of global information ethics: The road travelled and new horizons," Ethical Space: The International Journal of Communication Ethics, vol. 7, no. 2/3, pp. 2836, 2010.

[17] L. Floridi, "Information Ethics: An Environmental Approach to the Digital Divide," Philosophy in the Contemporary World, vol. 9, no. 1, 2001.

[18] D. Fallis, "Information ethics for twenty-first century library professionals," Library Hi Tech, vol. 25, no. 1, pp. 23-36, 2007.

[19] C. P. Chuang and J. C. Chen, "Issues in Information Ethics and Educational Policies for the Coming Age," Journal of Industrial Technology, vol. 15, no. 4, 1999.

[20] A. R. Peslak, "Current Key Privacy Factors: Development and Analysis," Journal of Information Technology Impact, vol. 6, no. 3, pp. 171-186, 2006.
[21] F. L. Wilczenski and S. M. Coomey, "Cyber-Communication: Finding Its Place in School Counseling Practice, Education,and Professional Development," ASCA, pp 327-331, 9:4 April 2006.

[22] S. Mahfood, A. Astuto, R. Olliges, and B. Suits, "Cyberethics Social Ethics Teaching in Educational Technology Programs," Communication Research Trends, vol. 24, no. 4, pp. 3-43, 2005.

[23] D. Pruitt-Mentle, "2008 National Cyberethics, Cybersafety, Cybersecurity Baseline Study", Educational Technology Policy Research and Outreach (ETPRO), National Cyber Security Alliance (NCSA), October 2008.

[24] J. X. Lin, "Educational Enlightenments from Internet Ethics Issues," Journal of Information, Technology and Society, 2003(2), pp. 65-72.

[25] F. Odabasi and E. B. Kuzu, "A Proposal For Ethics Training In Internet Cafes," in Proceedings of the 7th WSEAS International Conference on Education and Educational Technology, pp. 141-144, 2008.

[26] C. Fuchs, R. M. Bichler, and C. Raffl, "Cyberethics and Co-operation in the Information Society," Sci Eng Ethics, Vol. 15, pp. 447-466, 2009.

[27] T. A. Kraft and J. Carlisle, "Computer Ethics: A Slow Fade from Black and White to Shades of Gray," in Proceedings of Information Systems Educators Conference, 2010.

[28] A. Ramadhan and D. I. Sensuse, "e-Livestock as a New Paradigm in eGovernment," in Proceedings of the 3rd International Conference on Electrical Engineering and Informatics (ICEEI 2011), IEEE Press, vol. $1,2011$.

[29] Z. Fang, "E-Government in Digital Era: Concept, Practice, and Development," International Journal of The Computer, The Internet and Management, vol. 10, no. 2, pp. 1-22, 2002.

[30] A. Ramadhan, D. I. Sensuse, and A. M. Arymurthy, "Postmodernism in e-Government," International Journal of Computer Science Issues, vol. 8, issue. 4, no. 1, pp. 623-629, July 2011.

\section{AUTHORS PROFILE}

Arief Ramadhan. B.Sc in Computer Science (Bogor Agricultural University, Indonesia, 2005), M.Sc in Computer Science (Bogor Agricultural University, Indonesia, 2010), Ph.D Student in Computer Science (University of Indonesia), Research Assisstant at University of Indonesia. Member of eGovernment Lab at University of Indonesia.

Dana Indra Sensuse. B.Sc in Geology (Bogor Agricultural University, Indonesia, 1985), M.Sc in Library and Information Studies (Dalhousie University, Halifax, Canada, 1994), Ph.D in Information Studies (Toronto University, Canada, 2004), Lecturer at University of Indonesia, Head of eGovernment Lab at University of Indonesia.

Aniati Murni Arymurthy. B.Sc in Electrical Engineering (University of Indonesia, 1973), M.Sc in Computer and Information Sciences (Ohio State Univ., Ohio, USA, 1981), Ph.D in Computer Science (University of Indonesia, 1997), Professor at Faculty of Computer Science in University of Indonesia, Lecturer at University of Indonesia, Head of Pattern Rec, Image Proc, and CBIR Labs at University of Indonesia. 